\title{
The Joyce schemes and their importance to the first Ulysses translations in Russia of 1920-1930s
}

\author{
Svetlana N. Stepura
}

\section{DOI: 10.18355/XL.2016.09.02.103-113}

\begin{abstract}
The article reviews the world famous novel of the Irish writer James Joyce, "Ulysses", published in Paris in 1922 in terms of the study of its Russian reception regarding the schemes of the novel. In 1920-1921 Joyce compiled two schemes on "Ulysses": the first scheme was made for private use only; the second scheme was prepared for the public lecture on "Ulysses". Soon the information on the schemes became known to the press and in 1923 the information on "Ulysses" appeared in the Soviet press; the data source was mainly the French press. In 1924 and in 1929 the first "Ulysses" translations into French saw the light. In 1925 there was published the first Russian translation of "Ulysses" which was followed by four more translation attempts of 1929, 1934, 1935 and 1936; together they represented the system of "Ulysses" Russian reception. The study of this issue led to the Reception Theory as the methodological basis of the investigation. The scope of this research is the need to trace the influence of the Joyce's schemes on the first Russian translations of the 1920-1930s.
\end{abstract}

Key words: James Joyce, Ulysses, schemes, French publications, reception, the first Russian translations

\section{Introduction}

\section{Joyce's schemes}

James Joyce's novel "Ulysses" was published in English in Paris in 1922. It is a well-known fact that Joyce's novel gives the description of the events, recollections, feelings and thoughts that are perceived by the characters during one day. The novel comprises 18 episodes which mostly concentrate on the three main characters: a poet Stephen Dedalus, an adman Leopold Bloom and a concert singer Molly Bloom. Each episode refers to a certain chapter (song) of Homer's Odyssey that became the principle of complex Joyce's work. On the whole Joyce's novel is divided into three main parts. The first part called "The Telemachiad" consists of the first three episodes that represent the prologue with the Son major theme; it precedes the tale of Father's wanderings - the second part which is called "The Wanderings of Ulysses" - starts with the forth episode and ends with the fifteenth episode; its central character is Bloom. During these episodes a gradual rapprochement of Stephen and Bloom can be observed. "Nostos" or "Homecoming" is the third and final part of the novel in which Bloom comes closer to his home, spends the time with his "son", Stephen and brings him home. The final episode of "Homecoming" and of the entire novel is devoted to Bloom's wife as the wife's rightful place is at home; it also means that the wanderings are brought to a close, at least for this day.

To clarify some of his ideas Joyce made up two schemes of the novel. In this regard the main source of reference here is "Critical companion to James Joyce: A literary reference to his life and work" by Nicholas A. Fargnoli and Michael P. Gillespie. The first scheme had been written before the completion of the work on "Ulysses"; his second scheme was finished simultaneously with the novel's 
completion. In his letter dated September 21, 1920 Joyce wrote that due to the volume of the novel and its even greater complexity he planned to send his friend a kind of scheme, outline or clue for personal use only (Joyce, 1975: 271). Joyce defined his novel as an epic of two nations (Israel-Ireland) that combined the exposition of human body life cycle and the description of a single day (Fargnoli, 2006: 308). This letter was addressed to Carlo Linati, a friend of Joyce and the translator of his play "Exiles" into Italian. That's why the first scheme compiled approximately in 1920 is called Linati's scheme. The second scheme was given to Valerie Larbaud in 1921 to help him prepare for the public lecture on "Ulysses" (Fargnoli, 2006: 308). During the 1920 s these schemes were spread among Joyce's closest friends.

\section{Public awareness of Joyce's schemes}

In the early 1920s the information on schemes appeared in the press, presumably the French press. In 1923 in the Soviet magazine "Sovremenny Zapad" V. Azov wrote about "Ulysses" in regard to the schemes: inattentive or careless reader would read the novel to the end and remain convinced that the name of the main character of Odyssey had been mentioned by Joyce to no purpose (Azov, 1923). He also wrote about Valerie Larbaud, a French critic, writer, poet and translator, who was known to be devoted to the study of Joyce and who could easily separate the novels' framework or skeleton from its "living flesh" - thus the Soviet reader became aware of the fact that the novel was built entirely according to the Odyssey plan with BloomUlysses and Dedalus-Telemachus (Azov, 1923: 212).

Thus V. Azov having provided the information on the key to "Ulysses" wrote about the division of the novel into parts according to the Odyssey division into chapters (songs) and gave them Russian names correspondently. The choice of the names was based on the graphical plan of "Ulysses" drawn by V. Larbaud: above everything the reader could see three panels of "The Telemachiad"; the central part offered the "Twelve Adventures" and below there were three episodes of "Homecoming" (Azov, 1923). He also made it clear that the main character of "Ulysses" - Ulysses-Bloom didn't appear in the first part as it should be in accordance with Homer's "Odyssey", the readers' attention was focused on the "spiritual son" of Ulysses-Bloom - Telemachus-Dedalus. Then Joyce created twelve chapters relying on the basic songs of Homer's "Odyssey" that were closely connected with Ulysses-Bloom.

Therefore it became obvious that the Odyssey plan was the framework for Joyce's novel. V. Azov highlighted that Joyce made his novel even more complex by having created an outline for each episode separately: each chapter-episode had a certain branch of science and art; contained a single character (symbol); associated with a particular body organ; had a different colour as in the Catholic liturgy; had a different technical implementation and corresponded to a specific hour of the day. There was also given an example of dominants from the $7^{\text {th }}$ episode "Aeolus".

In 1920-1930s the information on Joyce's schemes was used by the Russian translators who had the chance to receive the mentioned source of information: the French and Russian periodicals on the Joyce's schemes. In general, for about a decade (1925-1936) there were five attempts executed to translate "Ulysses" into Russian.

\section{Methods}

The study of Joyce's works is still one of the current issues of modern literary criticism, that's why "the reconstruction and description of the reception history of Joyce's heritage in Russia" (Stepura, 2014: 361) is considered to be very important. The aim of this research in particular is to call attention to different interpretations of a single piece of art according to the Reception Theory or Reader- 
Response criticism as the very existence of a large number of "Ulysses" translations requires its application. W. Izer, one of the founders of the Reception Theory indicated the dialectical nature of reading when there is an interaction between the reader's and the author's horizon of expectation. The result of such interaction can be manifested in semantic ambiguity which is able to give the reader an opportunity for self-identification (Izer, 1978). When confronted with someone else's text the reader fills the areas of semantic uncertainty through their life and experience that had been formed as a part of their culture. This process can be interpreted as semantic interference which means that the reader generates the meanings on the basis of their culture (Amineva, 2015: 80). Here we do not consider the question of differences between the cultures rather come up to it from the other side as we are more interested in a great number of different approaches, different ways of perception to the same text. Besides, Izer also stated the point that there was no single or uniform code between the original text as the base and the addressee. This unequal ratio between the text and the reader has no distinct boundaries but namely the result of this uncertainty increases the diversity of potential communication methods.

More than that, it is thought to be very significant that the way of thinking in the beginning of the $20^{\text {th }}$ century known as the era of modernism was shared by America, Europe and Russia incl. (Stepura, 2014: 361).

\section{French publications on "Ulysses"}

In 1924 Valerie Larbaud's article on "Ulysses" was published in the French magazine «La Nouvelle Revue Française» and in the magazine "Commerce" there were published some episodes of "Ulysses" French translation (the $1^{\text {st }}$ episode "Telemachus", the passages from the $17^{\text {th }}$ and the $18^{\text {th }}$ episodes, "Ithaca" and "Penelope" respectively) fulfilled by Valerie Larbaud, Leon-Paul Fargue, Auguste Morel and Sylvia Beach. Thereafter Valerie Larbaud together with Auguste Morel and Stuart Gilbert took part in a full translation of "Ulysses" into French that was published in 1929 (Fargnoli, 2006: 280). It is also known that Stuart Gilbert's participation in this translation resulted in writing a special study of the novel, which was created under the guidance of Joyce himself. In 1930 Stuart Gilbert published his book "James Joyce's Ulysses" which offered an analysis of each episode of the novel. It emphasized the importance of using Homer's Odyssey as the structural frame of "Ulysses" (Fargnoli, 2006).

\section{Russian critiques and translations of "Ulysses" \\ 1.Russian translation of $\mathbf{1 9 2 5}$}

The first Russian translation of Joyce's "Ulysses" had been fulfilled in 1925 by V. Zhitomirsky (Zhitomirsky, 1925). The information on his life and work has not been found but it is known that he also took part in the translations from French into Russian. The publication of this translation was accompanied by the introduction whose role was to interpret the modernist writer's work in the right way, comment on the work of art, and fix artistic techniques and the author's position. The introduction was written by E. L. Lann, the editor of the almanac "Novinki Zapada" who informed about the work of Joyce briefly; presented the names of foreign authors and critics, book and journal titles in English and French; informed the readers that Joyce failed to print his novel in England thus giving the explanation why the publication of the novel took place in America and in France (Lann, 1925). The cause of scandalous history of "Ulysses" publication was not fully presented but might have been a good motivation for the Russian reader and critics. E. L. Lann wrote that none of the Anglo-Irish publishers agreed to publish "Ulysses" for Joyce's manner to speak freely of many things which was completely unacceptable in English society. The tradition

XLinguae Journal, Volume 9 Issue 2, April 2016, ISSN 1337-8384 
keepers of the English society put a veto on the novel and very soon it became practically impossible to buy the book though from time to time in the newspapers appeared the adverts that offered substantial sums for the book of Joyce (Lann, 1925: $61)$.

The readers were also offered the summary of "Ulysses" which was known to be divided into episodes; its translation also called "Ulysses" didn't have any division into episodes; the novel was presented as the work consisted of three parts without names given but their description in the summary was identical to the three parts of Joyce's work: 1- "The Telemachiad"; 2 - "The Wanderings of Ulysses"; 3 "Homecoming". E. L. Lann reported that the novel told about quite an ordinary day of mediocre Mr. Bloom. He considered the singularity of "Ulysses" to be in Joyce's attempt to tear the veils off a person and his soul. There were the citations of Ezra Pound, Richard Aldington, Valerie Larbaud and "Times" presented in the Introduction. Valerie Larbaud was given special attention; his name was mentioned in connection with the magazine "La Nouvelle Revue Française". E. L. Lann considered him to be one of the most remarkable writers of present-day France; the author of "A. O. Barnaboth".

Thus the introduction showed that the first Russian translator of "Ulysses", V. Zhitomirsky was familiar with the novel's schemes, the author's plans and intentions when working over the novel. The introduction also revealed one of the supposed tasks of the translator - to show the variety of styles used in "Ulysses".

The first Russian translation presented five fragments of the novel which had been chosen so that it would be possible to give at least a distant view of the author's stylistic devices (Lann, 1925). The original name of the novel and content abridgement of "Ulysses" text indicated the use of abstract translation: full written translation of the selected original parts comprising coherent text which form the abstract (summary) of an archetype. This kind of translation is usually aimed at familiarizing the reader with the key elements of the original. As a rule, abstract translation is used when making summary of the source in newspaper articles, press releases and other published materials. Abstract translation introduces a new perception form of a piece of art being at the same time a special way of presenting new foreign literature.

Those five fragments had been taken from the following "Ulysses" episodes: the $1^{\text {st }}$, the $7^{\text {th }}$, the $12^{\text {th }}$, the $17^{\text {th }}$ and the $18^{\text {th }}$. The first fragment was the beginning of the novel; the last one presented the novel's end. All fragments except the first one had the headings. So, the first fragment had no title and it is considered to be an attempt of the translator to attract the reader's attention to the title of the novel.

The second fragment is called "In the editorial office" - the seventh episode "Aeolus"; the third fragment is called "The conversation in the tavern" - the twelfth episode "Cyclops"; the fourth fragment is named "At Bloom's" - the seventeenth episode "Ithaca"; the fifth fragment is named "Marion Bloom is meditating in her bedroom" - the eighteenth episode "Penelope". The mentioned fragment titles do not match the informal headings of each of the novel episodes given by Joyce but they reflect their current events. Possibly, V. Zhitomirsky introduced his own titles to give an explanation of what was happening in the episodes.

The study of these translated fragments has given the reason to believe that they are connected at the structural level and united in terms of content. Since all "Ulysses" scenes are built around the three main characters Vladimir Nabokov identified them as triptych and defined Bloom as their central figure (Nabokov, 1998). It is justified by the fact that Stephen and Molly take side positions in the novel: the novel starts with Stephen's considerations and finishes with Molly's stream of consciousness. The triptych idea could arise on the basis of Valerie Larbaud's article 
and Valerie Larbaud could have acquired it from Joyce himself. Nabokov's triptych also corresponded to V. Azov's publication of 1923 who had introduced the French critic Valerie Larbaud to the Russian reader and who identified "Ulysses" scenes as "three panels" (Azov, 1923). Two storylines of the novel connected with the two main characters, Stephen Dedalus and Leopold Bloom, are united by their mutual spiritual search of a father and a son. Throughout the novel these two lines are developing parallel to each other but they hardly ever met: in the sixth and the seventh episodes Bloom can see Stephen at a distance but they don't meet; in the fourteenth episode the two lines are coming nearer but their meeting does not take place; in the fifteenth and the sixteenth episodes they are coming together but the action is delayed as "the conclusions will be made in "Ithaca" (Horujy, 2009: 951), in the seventeenth episode.

The two storylines in V. Zhitomirsky's translation can be seen in the following way: the first fragment introduces Stephen Dedalus; the second fragment presents Stephen who is already familiar to the reader and introduces Bloom; the third fragment is devoted to Bloom; the forth fragment shows Bloom and Stephen together; the fifth and final episode reveals the inner world of Bloom's wife, Molly.

V. Zhitomirsky's outline of "Ulysses" corresponded to Nabokov's triptych pattern as the main figures of the novel were shown in the order they were presented in the original: Stephen Dedalus - Leopold Bloom - Molly.

Thus V. Zhitomirsky tried to tell the Russian reader of the large Joyce's novel in a summary form and in the form of a collage at the same time. It was published in one issue of the almanac, in other words, in the magazine format thus presenting a single information product.

Therefore the specificity of V. Zhitomirsky's translation lies in its form - it can be classified as an abstract translation that conveys the basic idea of a piece of art. At the same time different styles presented in five fragments help the reader understand the art of the novel specificity: every single episode has its own art form. Special art forms of Joyce's novel had the purpose to reveal the content of each episode and of the novel itself. Thus the translator's attempt to show the diversity of styles in "Ulysses" was worthwhile as the writing techniques, the work with the language and literary forms in "Ulysses" were of paramount importance (Horujy, 2009: 781). This intention of Joyce was transmitted in the first Russian translation of 1925. Upon the whole, V. Zhitomirsky let the reader see the Joyce's novel in brief but the other translators of the period offered them only its separate episodes.

\section{Russian translation of 1929}

In 1929 in the newspaper "Literaturnaya Gazeta" there was published the second Russian translation of Joyce's novel which presented just two fragments taken from two different episodes. It was called "Ulysses" (Fragments)". The translation was fulfilled by S. Y. Alymov (a poet) and M. Yu. Levidov (a journalist, writer and playwright). The second "Ulysses" translation had been preceded by the Introduction written by the translators themselves. It told that the author of the novel, the Irish writer James Joyce, was one of the most remarkable representatives of postwar Western literature.

The novelty of his literary techniques having been recognized as exceptional and brought out in "Ulysses" earned him the fame of a "psycho genius" (Alymov, Levidov, 1929: 3). Joyce had used the words from different languages, created new word combinations; having refused to make his language flowery he created surprisingly concise, economical and intense style. S. Y. Alymov and M. Yu. Levidov also mentioned Joyce's manner of writing which might seem confusing but in fact it wasn't. "When you read carefully this seeming difficulty or confusion becomes fully justified" (Alymov, Levidov, 1929: 3).

XLinguae Journal, Volume 9 Issue 2, April 2016, ISSN 1337-8384 
The translators called "Ulysses" a work which presented the signpost or indicator of actions, moods, recollections, thoughts and tastes of Bloom, Dublin Jew, during 24 hours. They saw the author's task in the necessity to show the overall performance of the human brain for the day - skipping flow of thoughts without any omissions or exceptions. The translators also reported that the French and AngloAmerican critics compared Joyce's openness with Rabelais that could have been an explanation why Joyce's novel had been banned in England and America.

The translators observed that "Ulysses" had not been yet the subject of analysis of Marxist criticism that is why they thought that in future it might be regarded as alien to the interests and needs of the Soviet reader. The final words of the Introduction offered the personal viewpoints of the translators and of the editorial office as well. They ran the following: having placed some passages from the novel the editorial office intended to introduce the Soviet reader to the work of the most ingenious, unorthodox master of NEW LITERARY FORMS whose writing techniques could become of great significance for the Soviet reader (Alymov, Levidov, 1929: 3). Thus it is very important to note that the Introduction captured the essence of Joyce's novel, explained the choice of the passages and the way they should be figured out.

The passages chosen were some fragments of the fourth and the eighth episodes of "Ulysses": "Calypso" and "Lestrygonians". They had been numbered the first and the second. This translation of "Ulysses" differs significantly from the first translation of 1925 by the fact that it is the translation of separate episodes of the novel whereas V. Zhitomirsky sought to transfer the overall presentation of Joyce's novel fulfilled in brief. S. Y. Alymov and M. Yu. Levidov in their translational approach to the novel showed another potential of Joyce's text - potential of fragmentariness and kaleidoscopic effect. The choice of the fragmentary translation when only some pieces of the text are to be translated seems to be quite natural regarding the overall aesthetic context of the modernist novel.

\section{Russian translation of 1934-1935}

V. O. Stenich (a poet and translator) fulfilled the translation of three "Ulysses" episodes; the sixth episode ("Hades") named "The funeral of Patrik Dignam" was published in the magazine "Zvezda" (Leningrad) in 1934; the translation of the forth and the fifth episodes ("Calypso" and "Lotus Eaters") as an organic whole was published in 1935 under the title "Morning of Mr. Bloom" (A chapter from "Ulysses") in "Literaturny sovremennik", the most significant literary edition of Leningrad in 1930s.

The article of D. P. Mirsky (D. S. Mirsky) "About Ulysses” was published together with the Stenich translation of 1935. Despite the numerous references to the decadent bourgeois literature of the West the article was of great importance for the translation. D. P. Mirsky expressed his point of view on the novel; he translated the passages from different episodes of the novel into Russian when it was necessary to support some of his ideas. This fact allows us to guess that D. P. Mirsky had read "Ulysses" in the original and could debate with arguments with other critics. He wrote that the bourgeois critics and some of the Russian ones - mainly those who judged the unread books - put forward an argument against the Joyce method: art was based on the choice, unprincipled choiceless copying had never belonged to art. This argument was disputable for D. P. Mirsky as choiceless copying was impossible the same as it was impossible to copy the stream of consciousness as a matter of principle (Mirsky, 1935). Everything Joyce did to create the effect of the stream of consciousness was based on the choice and selection like any other forms of art. 
The article of D. P. Mirsky stood out among other critics' reasoning, among other forewords and commentaries that had been written earlier (V. Azov, E. L. Lann, S. Y. Alymov and M. Yu. Levidov). The detached view of D. P. Mirsky on the Joyce's novel was manifested in the fact that he didn't see any clear connection between "Ulysses" and Homer's "Odyssey"; he wrote about the Joyce's commentators that they were struggling to explain any relation between OdysseyUlysses of Joyce and Odyssey of Homer (Mirsky, 1935: 133). But in spite of that he gave the reader all the necessary information on the forth and the fifth episodes in their relation to Homer, the information that traditionally went with "Ulysses" translations.

D. P. Mirsky's description of Joyce's novel in its entirety was the exposition of a modernist work in its essence. It was a kind of educational article about modernism but cleverly disguised. In spite of all the charges of "perverse pleasure" and "formal embellishments" that have nothing to do with the "natural beauty"; of the use of "ugly and disgusting" images and despite the fact that the word "modernism" had never been used by D. P. Mirsky, the article reconstructed the typical product of modernism with the help of such definitions as "mythologizing the surrounding area" (Mirsky, 1935: 131), "sublimation" (Mirsky, 1935: 132), a person as an "isolated atom, individuality" without any relation to society (Mirsky, 1935: 133), the reduction of classical heroics, the tendency to the "passivity and decadent aesthetization" (Mirsky, 1935: 135). The article also explained that the fragment from the Joyce's novel included the first two episodes of the second part of "Ulysses" thus interpreting the translator's choice of the material: the first part was very short, devoted to a poet Stephen Dedalus, the author's counterpart; the beginning of the second part "The Wanderings of Ulysses" introduced the second protagonist of the novel, Leopold Bloom (Mirsky, 1935: 131). So, the events of the first part of the novel were presented from Stephen's point of view; there Joyce appeared to be the follower, the one who completed the line of aesthetic naturalism that dated back to "artistic writing" (écriture artiste) of G. Flaubert and de Goncourt. The first three episodes of the first part of "Ulysses" having described the world through the mind of Stephen showed the power of Joyce over the "exact word" (mot juste) (Mirsky, 1935: 131). There was no deforming reproduction of the surrounding world, no irony or parody. The transition from the first part of the novel to the first episode of the second part namely the forth episode "Calypso" showing Bloom for the first time introduced the different atmosphere: from the artistic consciousness of Stephen to the prosaic thinking of Bloom. The first appearance of Bloom signalized the first manifestation of new features inherent in modernism.

It is necessary to note that two translations of S. Y. Alymov, M. Yu. Levidov and later, of V. O. Stenich being in some way connected with the forth episode "Calypso" are one of the most striking features of Joyce reception in Russian literature of 1920-1930s. The choice of the forth episode of Joyce's novel can be explained by the fact that D. P. Mirsky mentioned in his article - the forth episode is the starting point of steady development of aesthetics and poetics in modernism. The similarity between the translations can be also marked with the fact they both had been integrated into one fragment (Alymov, Levidov - the passages from the forth and the eight episodes, "Calypso" and "Lestrygonians"; V. O. Stenich - the passages from the forth episode "Calypso" and the fifth episode "Lotus Eaters").

In this way the guideline of S. Y. Alymov and M. Yu. Levidov to create the original author fragmented translation of "Ulysses" adequate to its modernist nature was continued by V. O. Stenich. Besides, V. O. Stenich like his forerunner, V. Zhitomirsky, gave their own names to the translated episodes. 
On the other hand, V. O. Stenich was the first Russian translator who didn't make an abstract translation like V. Zhitomirsky or abridged translation like S. Y. Alymov and M. Yu. Levidov but fulfilled a full translation of single episodes.

The sixth episode of "Ulysses" translated by V. O. Stenich was published in 1934, the year before "The morning of Mr. Bloom". It was called "The funeral of Patrik Dignam". In this case there was used the approach to "Ulysses" translation in its kaleidoscopic and fragmentary aspect.

Having been chosen from the entire novel this episode presented a selfsustained piece of art about death, decay and universal destruction: "this is the message of self-abnegation", "the tendency to the destruction of the material world and laws of human thought, the desire to transform life into chaos" (MillerBudnitskaia, 1934: 138). As a matter of fact, all mentioned characteristics of the sixth episode embody the essence of modernism.

The commentary to this translation was written by R. Miller-Budnitskaia; it was aimed at criticism of bourgeois innovative art in the face of Joyce, at the description of interior monologue or stream of consciousness as a literary device, it gave brief information about the time and the scene of the episode. It also presented church-scholastic system of symbols in "Ulysses" which included the symbology of colour, body organs, sciences and arts (Miller-Budnitskaia, 1934: 140).

The sixth episode in the Russian translation of 1934 reproduced the form of the novel, all the images and horrifying pictures that had been depicted by Joyce. The translation also spoke of the translator's special interest to the form of the episode and to the novel as a whole.

\section{A. Kashkin team translation of 1935-1936}

In 1935-1936 in Moscow in the magazine "Internatsionalnaya literatura" there were published ten episodes of "Ulysses". It was the first attempt of a holistic translation of Joyce's novel into Russian and what is more important it was also completed in the era of the novel's creation. The translation had been fulfilled by the team of eight translators - "The first translation union of I. A. Kashkin" (I. K. Romanovich, L. D. Kislova, An. Eleonskaya, V. M. Toper, N. A. Volzhina, E. D. Kalashnikova, N. L. Daruzes, O. P. Holmskaya). In 1937 the work on the translation was discontinued due to the arrest of I. K. Romanovich; only the first ten episodes of "Ulysses" had been translated.

The Foreword of the first episode published had special data on Joyce's novel: time of "Ulysses" creation and publication; its connection to the earlier Joyce's novel "A portrait of the artist as a young man"; an explanation of the novel's title as a modern "Odyssey"; the original correspondence of "Ulysses" episodes to the songs of Homer's "Odyssey". It also stated that the main figure of the first three "Odyssey" songs was Odyssey's son, Telemachus; Odyssey himself appears for the first time only in the fourth song. The reader was also informed of Joyce's critics, Valerie Larbaud and Stuart Gilbert who considered Stephen Dedalus to be the analogue of Telemachus and Leopold Bloom to be the analogue of Odyssey. But the reference material was mostly based on the book of Stuart Gilbert (Gilbert, 1930).

Each successive episode published in "Internatsionalnaya literatura" had the Commentary to the translation with detailed information on the episode dominants and reference details such as the time and the place of the action; it gave an explanation of the places in the text of "Ulysses" translation which were supposed to be difficult for understanding; it ran that according to the scheme of Gilbert the "Ulysses" episode had its own art; it was made clear that the term (art) was used in its medieval meaning, that's why it included the sciences, etc. (Joyce, 1935: 50). 
Each of the translated episodes of Joyce's novel was accompanied by brief historical and cultural information.

\section{Conclusion}

The reader's reception of a piece of art is determined by a variety of interpretative models of perception. A translator is always primarily a reader that's why the translation results can be unpredictable. Russian translation reception of Joyce's "Ulysses" is remarkable and unexpectedly specific as just in one decade several translators, including the creative team turned to the novel to make its translation into Russian. This phenomenon as a whole can be classified as "Russian "Ulysses" of 1920-1930s.

As it can be observed the interpretative models of "Ulysses" in the first Russian translations were extremely diverse. Abstract translation of V. Zhitomirsky gave the reader the core of Joyce's novel in a brief form. It consisted of the fragments from five different episodes combined by common motives; it also gave an overview of the novel. At the same time every single fragment showed the style and the technique of a translated episode. In fact, Joyce tried to solve the problems on the content with the help of a specific art form, in substance, with diversity of forms.

Translations of S. Y. Alymov and M. Yu. Levidov (1929) and of V. O. Stenich (1934-1935) are defined by the choice of separate episodes; in the first case they were also the fragments of the episodes but in the latter case they were the entire episodes taken as a whole.

The translation of 1929 presented the combination of fragments from two different episodes integrated due to the general principles of naturalism and stream of consciousness. It had been an ingenious presentation of Joyce's work in Russian: the fragments of two different episodes taken as a whole; in other words, it was a smallscale but finished product in its own way; Leopold Bloom and his physiology in the spotlight.

V. O. Stenich took three successive episodes for his translation; they were the first three episodes of the second part "The Wanderings of Ulysses" in which Leopold Bloom was in the focus again. The gist of the translation was to show the specifics of the novel's form through the depiction of stream of consciousness of its character Ulysses-Bloom.

So, fragmentary translations of S. Y. Alymov, M. Yu. Levidov and V. O. Stenich had implemented such features of modernist text as fragmentariness and kaleidoscopic effect.

The aim of the translation of 1935-1936 fulfilled by I. A. Kashkin team was to translate the entire novel. This team stood by the so-called "creative translation" which helped them to present the fullness of "Ulysses" form and content.

On the whole the first Russian translations of Joyce's "Ulysses" of 19201930 -s are defined as a complex combination of verbal and creative translation with a certain purpose to introduce the novel's modernist form (pattern).

Against the background of a complex and often conflicting attitudes towards the innovative novel of Joyce in European and American culture and literature of the beginning of the $20^{\text {th }}$ century in Russia of the same period took shape the framework of receptive texts related to Joyce's novel "Ulysses" which allowed to speak on the phenomenon of Russian modernism such as "Russian "Ulysses" of 1920-1930s.

Therefore, Joyce had made the "Ulysses" schemes to clarify the meaning of the novel's events, indicating that each episode of "Ulysses" had a direct relation to the poem of Homer and was defined by special semantic dominants. The schemes of Joyce given to his friends, literati and translators, directed their hermeneutical activity without revealing all novel's secrets and puzzles; it recreated the structural novel

XLinguae Journal, Volume 9 Issue 2, April 2016, ISSN 1337-8384 
framework which was necessary for the understanding of the whole piece and every single episode of the novel. Taking into consideration the very fact of semantic ambiguity and dialectical nature of reading and assuming that the translators are always the first readers of the text to be translated, the readers who are supposed "to grasp certain meanings and present them in a way intelligible to the majority of people - to which the reader of the text also belongs" (Janeková, 2014: 62), we may conclude that translation interpretations of "Ulysses" cannot be limited by a single version. All translators of "Ulysses" of the mentioned period were aware of the Joyce schemes and the outcome of their awareness had been realized in different translation versions of "Russian Ulysses". So to say, they worked strictly within the framework created by Joyce's schemes yet all mentioned translations had their own distinctive features.

\section{Bibliograpic references}

ABSTRACT TRANSLATION. 2003. In Tolkovy perevodchesky slovar. Ed. by L. Nelubin. Moscow, p. 182.

AMINEVA, V. et al. 2015. G. Tukay's Poetry: the Aspects of National Identity. In XLinguae, European Scientific Language Journal, vol. 8, n1, pp. 79-87. ISSN 13378384.

AZOV, V. 1923. James Joyce. In Sovremenny Zapad. Moscow - Petrograd, № 4, pp. 210-212.

FARGNOLI, N. - GILLESPIE, M. 2006. Critical Companion to James Joyce: A Literary Reference to his Life and Work. New York: Infobase Publishing, pp. 465.

GILBERT, S. 1930. James Joyce's Ulysses. London, 450 p.

HORUJY, S. 2009. Commentary. In Ulysses by James Joyce. St. Petersburg, pp. 779984. ISBN 978-5-9985-0459-4.

IZER, W. 1978. The Act of Reading: A Theory of Aesthetic Response. Baltimore, John Hopkins UP. 239 p.

JANECOVA, E. 2014. Word and Image in Contemporary Writing: Curiosities in Mark Haddon's The Curious Incident of the Dog in the Night-Time. In XLinguae: European Scientific Language Journal, vol. 7, n. 1, p. 60-64. ISSN 1337-8384.

JOYCE, J. 1925. Ulysses. Translated by V. Zhitomirsky. In Novinki Zapada. Moscow - Leningrad, № 1, pp. 65-94.

JOYCE, J.1929. Ulysses (Fragments). Translated by Alymov S., Levidov M. In Literaturnaya gazeta. Moscow, № 20, p. 3.

JOYCE, J. 1935. Ulysses (2). Translated by Kislova L. In Internatsionalnaya literature. Moscow, № 2, p. 50.

JOYCE, J. 1975. Selected Letters. Ed. by Richard Elmann. London, p. 271.

LANN, E. 1925. James Joyce. In Novinki Zapada, Moscow-Leningrad. № 1, pp. 6164.

MILLER-BUDNITSKAIA, R. 1934. The Commentary to the Funeral of Patrik Dignam. In Zvezda. Leningrad, № 11, p. 137-142.

MIRSKY, D. 1935. About Ulysses. In Literaturny sovremennik. Leningrad, № 5, p. 131-135.

MISTEROVA, I. 2015. The Reception of Anglo-American Drama During the Great War in Period Newspapers. In XLinguae: European Scientific Language Journal, vol. 8, n.1, p. 88-100. ISSN 1337- 8384.

NABOKOV, V. 1998. James Joyce. In Lectures on Foreign Literature. Austen, Dickens, Flaubert, Joyce, Kafka, Proust, Stephenson. Moscow, pp. 367-468.

STEPURA, S. 2014. James Joyce's Ulysses in Periodical Literature of the 1910-1930s (The Interaction of American, European and Russian Cultures). In Virtual Multidisciplinary Conference QUAESTI. December, 15-19. EDIS - Publishing 
Institution of the University of Zilina, vol. 2, pp. 362-365. ISSN 1339-5572, ISBN 978-80-554-0959-7.

Words: 6258

Characters: 38925 (21, 63 standard pages)

Assoc. Prof. Svetlana N. Stepura, Ph.D.

Department of Foreign Languages, Institute of Cybernetics

National Research Tomsk Polytechnic University

Lenin Avenue 30, 634050 Tomsk

Russia

lana3670@rambler.ru 